\title{
Direct interaction of receptor tyrosine kinases, EphA4 and PDGFR $\beta$, plays an important role in the proliferation of neural stem cells
}

This article was published in the following Dove Press journal:

Journal of Neurorestoratology

6 July 2017

Number of times this article has been viewed

\author{
Qingfa Chen' \\ Takahiro Sawada ${ }^{2}$ \\ Kazushige Sakaguchi ${ }^{2}$ \\ Fabin $\mathrm{Han}^{1,3}$ \\ 'Centre for Stem Cells and \\ Regenerative Medicine, The Institute \\ for Tissue Engineering \& Regenerative \\ Medicine, The Liaocheng People's \\ Hospital/Liaocheng University, \\ Liaocheng, People's Republic of \\ China; ${ }^{2}$ Department of Molecular \\ Cell Biology and Molecular Medicine, \\ Institute of Advanced Medicine, \\ Wakayama Medical University, \\ Wakayama, Japan; ${ }^{3}$ Centre for Stem \\ Cells and Regenerative Medicine, The \\ Institute of Translational Medicine, \\ The Second Hospital of Shandong \\ University, Jinan, Shandong, People's \\ Republic of China
}

\begin{abstract}
Receptor tyrosine kinases mediate the extracellular signals and transmit them into the cytoplasm by activating intracellular proteins through tyrosine phosphorylation. Both Ephs and platelet-derived growth factor (PDGF) receptors (PDGFRs) have been implicated in neurogenesis, but the functional interaction between these two pathways is poorly understood. Here, we demonstrated that EphA4 directly interacts with PDGFR $\beta$ and mutually activates each other when expressed in HEK293T cells. H9-derived neural stem cells express Ephs and PDGFRs, and their proliferation is stimulated by ephrin-A1 and PDGF-BB with further augmentation by their combined application. As both EphA4 and PDGFR $\beta$ play important roles in preventing neurodegeneration and promoting neuroprotection, their interaction and transactivation might transduce the signal through the EphA4/PDGFR $\beta$ complex and augment the proliferation of neural stem cells.
\end{abstract}

Keywords: EphA4, PDGFR $\beta$, neural stem cell, transactivation, proliferation

\section{Introduction}

Receptor tyrosine kinases (RTKs) constitute a distinct family of transmembrane proteins present only in multicellular animals. These proteins transduce extracellular signals into the cytoplasm and are implicated in regulating cell growth, proliferation, migration, differentiation, and apoptosis. ${ }^{1-4}$ As the largest RTK subfamily, Eph receptors have type A and B subclasses according to their specificity to bind with their ligands, ephrins. ${ }^{5}$ In general, EphAs are bound with ephrin-As and EphBs are bound with ephrin-Bs; however, cross-specificity is also present. The ephrin-A class of ligands has a glycosyl phosphatidylinositol linkage to contact the cell membrane, whereas the ephrin-B class of ligands has a different structure containing a short cytoplasmic and transmembrane domain. Cell-cell contact-dependent signaling pathway from ephrins to Ephs (forward signaling) or from Ephs to ephrins (reverse signaling) regulates many physiological and developmental processes. Bidirectional signaling possesses many functions, including neural stem cell maintenance and plasticity regulation in the proliferation zone of adult brain, ${ }^{6,7}$ neuron migration, ${ }^{8}$ axon guidance, ${ }^{9}$ angiogenesis, ${ }^{10}$ bone homeostasis, ${ }_{11}^{11}$ embryonic patterning, ${ }^{12}$ tumorgenesis, ${ }^{13-18}$ insulin secretion, ${ }^{19}$ and so on. EphA4 expression is very high in the brain, and recently, EphA4 has been proposed to be implicated in Alzheimer's disease (AD), ${ }^{20,21}$ Parkinson's disease (PD), ${ }^{22,23}$ amyotrophic lateral sclerosis (ALS), ${ }^{24}$ and other neurodegenerative diseases. Hence, EphA4 may have functions for protecting neuron loss and reversing the aging cells. To further explore the EphA4-mediated signaling pathways and their biological functions 
in the brain, one important thing is to detect the signaling molecules interacting with EphA4.

Platelet-derived growth factor (PDGF) family of RTKs represents another signaling pathway. PDGF growth factors include four distinct subclasses (A-D) that bind to their receptors, PDGFR $\alpha$ and PDGFR $\beta$, after dimerization. ${ }^{25-27}$ PDGF, as a novel factor for neuron protection and neuron growth, plays a key role in regulating neurogenesis and hence is the mutation target of neurodegenerative diseases. ${ }^{28-31}$ Bush et al reported that PDGF-BB is implicated in playing key roles in neural stem/progenitor cell (NPC) proliferation and neurogenesis under the condition of HIV-associated neurological disorders. They observed that PDGF-BB could restore the hippocampal NPC proliferation through cognate receptors of HIV Tat-cocaine. PDGF-BB also regulates NPC proliferation and neurogenesis through miR-9/MCPIP1 axis. ${ }^{29,32}$ Zachrisson et $\mathrm{al}^{33}$ found that PDGF-BB is effective in counteracting histological, behavioral, and biochemical changes in the experimental rat model of PD. Treatment with PDGF-BB normalized the rotational behavior, and the effect lasted for 10 weeks. Paul et $\mathrm{al}^{34}$ found that intracerebroventricular (ICV) injection in PD individuals was tolerated well at all doses tested, supporting PDGF-BB as a proper candidate for further treatment of PD patients.

We have previously reported that ephrin-A1 injection reverses neuronal regeneration and alleviates the symptoms in a 6-OHDA-lesioned PD rat model, ${ }^{23}$ and that the interaction of EphA4 and FGFRs promotes mouse embryonic NPC proliferation and neurogenesis via FRS2 $\alpha$ and ERK1/2 downstream of the FGF/FGFR signaling. ${ }^{35,36}$ Here, we found that EphA4 and PDGFR $\beta$ have a direct interaction and can transactivate each other when coexpressed in cells. PDGF$\mathrm{BB}$ and ephrin-A1 appear to enhance proliferation of neural stem cells, suggesting that these ligands might be good candidates for curing neurological diseases such as AD and related disorders in human.

\section{Materials and methods}

\section{Reagents}

Recombinant human PDGF-BB (Cat. \#220-BB), recombinant human ephrin-A1-Fc (Cat. \#6417-A1), and recombinant human $\operatorname{IgG}(\mathrm{Fc})$ were purchased from $\mathrm{R} \& \mathrm{D}$ Systems, Inc. (Minneapolis, MN, USA). In this study, we used clustered ephrin-A1-Fc in which $1 \mathrm{mg}$ ephrin-A1 was oligomerized via incubation with $2.4 \mathrm{mg}$ of recombinant human $\operatorname{IgG}(\mathrm{Fc})$ for $>1 \mathrm{~h}$ according to the manufacturer's instructions. PDGFR inhibitor STI571 was purchased from Selleck (Munich, Germany). The following primary antibodies were used in this study: mouse anti-HA, rat anti-HA (Hoffmann-La Roche Ltd., Basel, Switzerland; 1:4,000); mouse anti-FLAG M2 (Sigma-Aldrich, St Louis, MO, USA; 1:4,000); rabbit antiEphA4, rabbit anti-PDGFR $\beta$, and mouse anti-GFP (Santa Cruz Biotechnology Inc., Dallas, TX, USA; 1:2,000); and mouse anti-phosphotyrosine (EMD Millipore, Billerica, MA, USA; $1: 4,000$ ).

\section{Cell culture}

Mammalian HEK293T cells (Clontech, Mountain View, CA, USA) were cultured as previously reported. ${ }^{37}$ Neural stem cells derived from $\mathrm{H} 9$ human embryonic stem cells (H9-NSCs) were obtained from Thermo Fisher Scientific (Waltham, MA, USA) and cultured following the manufacturer's protocols..$^{38}$ Cells were passaged to generation 3 for RNA extraction, cell proliferation assay, or immunoprecipitation and immunoblotting.

\section{Reverse transcription (RT)-polymerase chain reaction (PCR)}

H9-NSCs were rinsed with PBS after 3-day culture. The cells were homogenized using TRI Reagent (Sigma-Aldrich; Cat. \#T9424), and total RNA was then extracted using standard methods. RT and subsequent PCR were performed using the conditions as previously reported..$^{36}$ The product sizes and the forward and reverse primer sequences are presented in Table 1.

\section{Plasmid transfection}

EphA4 and PDGFR $\beta$ eukaryotic expression vectors were constructed as previously reported. ${ }^{37,39}$ Mutants of EphA4 and PDGFR $\beta$ plasmids were constructed using QuikChange Lightning Site-Directed Mutagenesis Kit (Stratagene, Santa Clara, CA, USA) following standard instructions. Plasmid transient transfection was performed using PerFectin (Genlantis, San Diego, CA, USA) into HEK293T cells. Before ligand stimulation, HEK293T cells or H9-NSCs were starved in serum-free medium containing $0.5 \%(\mathrm{~m} / \mathrm{v})$ bovine serum albumin (Sigma) for $5 \mathrm{~h}$.

\section{Immunoprecipitation and immunoblotting}

Cells were harvested in lysis A buffer with $50 \mathrm{mM}$ 4-(2-hydroxyethyl)-1-piperazineethanesulfonic acid buffer, $1 \%$ Triton X-100, $5 \mathrm{mM}$ ethylene diamine tetraacetic acid, $50 \mathrm{mM}$ sodium chloride, protease inhibitors $(1 \mu \mathrm{M}$ pepstatin A, $1 \mathrm{mM}$ phenylmethylsulfonyl fluoride, $1 \mu \mathrm{M}$ leupeptin, and $1 \mu \mathrm{M}$ aprotinin), and phosphatase inhibitors (50 mM sodium fluoride, $10 \mathrm{mM}$ sodium pyrophosphate, and $1 \mathrm{mM}$ sodium orthovanadate). Immunoprecipitation was 
Table I Primers used in this research

\begin{tabular}{|c|c|c|c|}
\hline Primer & Sequence $\left(5^{\prime}-3^{\prime}\right)$ & Length (bp) & NCBI code \\
\hline hEphal-F & ATGCACTGCAGCCCTGATGG & 644 & NM_005232 \\
\hline hEphal-R & CTCGGTTCTTTCTTCACCAG & & \\
\hline hEpha2-F & GTTCACCAAGATTGACACCA & 791 & NM_00443I \\
\hline hEpha2-R & TAGTTCATGTGGGGCTCCAG & & \\
\hline hEpha3-F & CAGCCAGCGATGTATGGAGT & 463 & NM_005233 \\
\hline hEpha3-R & GTGACACCAACCTTTTTCAT & & \\
\hline hEpha4-F & TCGAGGCTCCTGTGTCAACAACTC & 642 & NM_004438 \\
\hline hEpha4-R & GATGATGGTGCTGCTTGGTTG & & \\
\hline hEpha5-F & CATGTGCAAGGCAGGATATG & 623 & NM_004439 \\
\hline hEpha5-R & CATTGGGACGATCTGGTTCT & & \\
\hline hEpha6-F & TTCTGACATGGCAGCAGAAC & 483 & NM_00I080448 \\
\hline hEpha6-R & ACAACCCCTTCTAGGCGAAT & & \\
\hline hEpha7-F & GGAAAAATTCCAGTAAGGTG & 518 & NM_004440 \\
\hline hEpha7-R & АТСССТАААСТСАТСАСАТС & & \\
\hline hEpha8-F & GCCAGTTCCTCAAAATCGAC & 608 & NM_020526 \\
\hline hEpha8-R & TGTCCCATTCACACTGGAGA & & \\
\hline hEpha I0-F & ATGCCCATGATGAAGAGGAG & 556 & NM_001099439 \\
\hline hEphal0-R & ATCTTGCAGACAAGGTCGCT & & \\
\hline hEphbI-F & TCAGTGGCAAGATGTGCTTC & 365 & NM_00444I \\
\hline hEphbI-R & CAAACGCCCCTTGTACACTT & & \\
\hline hEphb2-F & TGAGTCAAGCCAGAACAACT & 542 & NM_017449 \\
\hline hEphb2-R & GCCGTCCCCGTTACAGTAGA & & \\
\hline hEphb3-F & ACCCCAATATAATCCGGCTC & 463 & NM_004443 \\
\hline hEphb3-R & TGGTTGCTCATGTCCCAGTA & & \\
\hline hEphb4-F & AAGCAGAGCAATGGGAGAGA & 575 & NM_004444 \\
\hline hEphb4-R & ACTTTGCAGACGAGGTTGCT & & \\
\hline hEphb6-F & GGGCAGCCCCAGAGGTCATT & 473 & NM_004445 \\
\hline hEphb6-R & GCTGAGCTGAGCCACATCAC & & \\
\hline hGapdh-F & GAGTCAACGGATTTGGTCGT & 512 & NM_002046 \\
\hline hGapdh-R & TGTGGTCATGAGTCCTTCCA & & \\
\hline hEfna I-F & CCATGACAATCCACAGGAGA & 592 & NM_004428 \\
\hline hEfna I-R & GGCTTCCAAGCAAGAAACTG & & \\
\hline hEfna2-F & TGGAGGTGAGCATCAATGAC & 384 & NM_00I405 \\
\hline hEfna2-R & TATTGCTGGTGAAGATGGGC & & \\
\hline hEfna3-F & TCTGGATATTTACTGCCCGC & 414 & NM_004952 \\
\hline hEfna3-R & TCCAGCACGTTGATCTTCAC & & \\
\hline hEfna4-F & TGGGCCTCAACGATTACCTA & 584 & NM_005227 \\
\hline hEfna4-R & AATGCTCCATCTTGTCGGTC & & \\
\hline hEfna5-F & TACCTGGATGTTTTCTGCCC & 546 & NM_001962 \\
\hline hEfna5-R & TGTGACAAGTGATGGGAGGA & & \\
\hline hEphexin I-F & ACCAAGAAGCTCTTCCACGA & 524 & NM_019850 \\
\hline hEphexin I-R & CATTCCTTGAGGTTCTGGGA & & \\
\hline hFrs2a-F & ATGAACGAAGAGATGCACCC & 502 & NM_006654 \\
\hline hFrs2a-R & AGGGGAGTTGTAGGCGTTTT & & \\
\hline hFgfr I-F & ATGGTTGACCGTTCTGGAAG & 481 & NM_00II 74066 \\
\hline hFgfrl-R & CTTCACAGCCACTTTGGTCA & & \\
\hline hFgfr2-F & GTCCCATCTGACAAGGGAAA & 522 & NM_000I4I \\
\hline hFgfr2-R & TGTTACCACCATACAGGCGA & & \\
\hline hFgfr3-F & CTGAAAGACGATGCCACTGA & 435 & NM_000I42 \\
\hline hFgfr3-R & GCCGTTGGTTGTCTTCTTGT & & \\
\hline hFgfr4-F & CAAAGACAACGCCTCTGACA & 516 & NM_0020II \\
\hline hFgfr4-R & ATCCCAAAAGACCACACGTC & & \\
\hline hPdgfra-F & AATCTGGACACTGGGAGATTCG & 381 & NM_006206 \\
\hline hPdgfra-R & TGGCAGAGGATTAGGCTCAG & & \\
\hline hPdgfrb-F & AGGATCGCTCTGTGAGCAAC & 346 & NM_002609 \\
\hline hPdgfrb-R & TССТССТTАСТGСССТСТСС & & \\
\hline
\end{tabular}


performed with indicated antibodies overnight at $4{ }^{\circ} \mathrm{C}$; after a wash for three times in washing buffer, immunoblotting was performed with diluted primary antibodies following the manufacturer's instructions using the standard procedure. ${ }^{37}$ To confirm reproducibility, experiments were performed more than once.

\section{Cell proliferation assay}

Cell proliferation was measured using a CellTiter96 Aqueous One Solution Cell Proliferation Assay (MTS) kit (Promega, Madison, WI, USA) according to the manufacturer's protocol. In brief, cells $\left(1 \times 10^{3}\right)$ were starved overnight and then seeded on 96-well plastic plates in a normal medium with growth factors. The indicated ligands (PDGF-BB, $20 \mathrm{ng} / \mathrm{mL}$; ephrin-A1, $0.5 \mu \mathrm{g} / \mathrm{mL}$ ) were added into the culture wells in a medium free of growth factors. After cultured for 3 days in the new media at $37^{\circ} \mathrm{C}$, the cells were further incubated with CellTiter96 Aqueous One Solution Reagent for $1 \mathrm{~h}$. The absorbance was recorded at $490 \mathrm{~nm}$ wavelength using a 96-well plate reader (iMark ${ }^{\mathrm{TM}}$; Bio-Rad Laboratories Inc., Hercules, CA, USA).

\section{Statistical analysis}

Data are analyzed using Graphpad Prism 6 by two-way ANOVA followed by Dunnett's multiple comparison tests. A value of $p<0.0001$ was considered as statistically significant difference. All the values were expressed as mean \pm SD.

\section{Results}

\section{Interaction between EphA4 and PDGFR $\beta$}

To evaluate the interaction between PDGFR $\beta$ and EphA4, both molecules were overexpressed in HEK293T cells, and their binding was examined using the immunoprecipitation and immunoblotting method. pcDNA3.1 plasmid was used to equalize the total amount of DNA in each transfection. As shown in Figure 1, the endogenous PDGFR $\beta$ was detected difficultly by immunoblotting with a specific antibody, while PDGFR $\beta$ expression level increases strongly under the elevated amount of exogenous PDGFR $\beta$, and a complex formation of EphA4 and PDGFR $\beta$ was detected by immunoblotting followed by immunoprecipitation using the antibodies shown. The result also demonstrated that their direct interaction is in their protein dose-dependent fashion.

\section{Transphosporylation between EphA4 and PDGFR $\beta$}

To investigate the functional consequences of ectopically expressing PDGFR $\beta$ and EphA4 and their subsequent complex formation, we next analyzed the transphosphorylation of

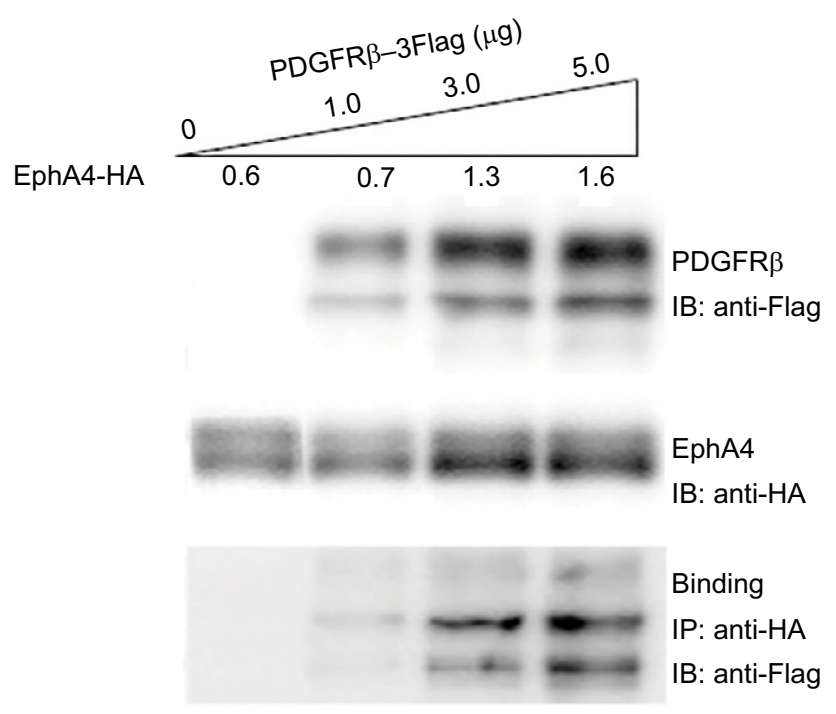

Figure I Complex formation of EphA4 and PDGFR $\beta$ in transfected HEK293T cells. Notes: HEK293T cells were cotransfected with pcDNA/EphA4-HA $(0.6,0.7,1.3$, and $1.6 \mu \mathrm{g}$ per $6 \mathrm{~cm}$ plate, respectively) and increasing concentrations $(0,1.0,3.0$, and $5.0 \mu \mathrm{g}$ per $6 \mathrm{~cm}$ plate) of pCDNA/PDGFR $\beta$-3Flag. Direct interaction was detected by SDS-PAGE and IB using anti-Flag antibody following IP using anti-HA antibody.

Abbreviations: IB, immunoblotting; IP, immunoprecipitation; PDGFR $\beta$, plateletderived growth factor receptor $\beta$; SDS-PAGE, sodium dodecyl sulfate polyacrylamide gel electrophoresis.

EphA4 and PDGFR $\beta$ when transiently coexpressed in mammalian cells. We overexpressed EphA4 expression vector in HEK293T cells together with expression vector for PDGFR $\beta(\mathrm{KD})$, a kinase-inactive mutant of PDGFR $\beta$ in which an Ala residue was substituted for Tyr-634 (Figure 2A).$^{40}$ Immunoblotting with an antiphosphotyrosine antibody followed by immunoprecipitation with a specific antibody of the kinase-inactive mutant of PDGFR $\beta$ in cells coexpressing EphA4(WT) has verified that EphA4 selfphosphorylated by overexpression in HEK293T cells causes the activation of kinase-inactive PDGFR $\beta$ mutant through tyrosine phosphorylation. Meanwhile, expression vector for PDGFR $\beta$ (WT) was ectopically transfected in HEK293T cells together with the expression vector for EphA4(KD), a kinase-inactive mutant of EphA4 in which a Met residue was substituted for Val-653. The experiment also shows that PDGFR $\beta$ in HEK293T cells activated by exogenous transfection induces the kinase-inactive EphA4 mutant tyrosine phosphorylation (Figure 2B).

\section{Inhibition of the interaction between EphA4 and PDGFR $\beta$ by an EphA4 dominant-negative mutant, EphA4 $(\Delta \mathrm{J} M, \mathrm{KD})$}

EphA4( $\triangle \mathrm{JM}, \mathrm{KD})$, in which 591-602 amino acids were deleted and a Met residue was substituted for Val-653, was 
A

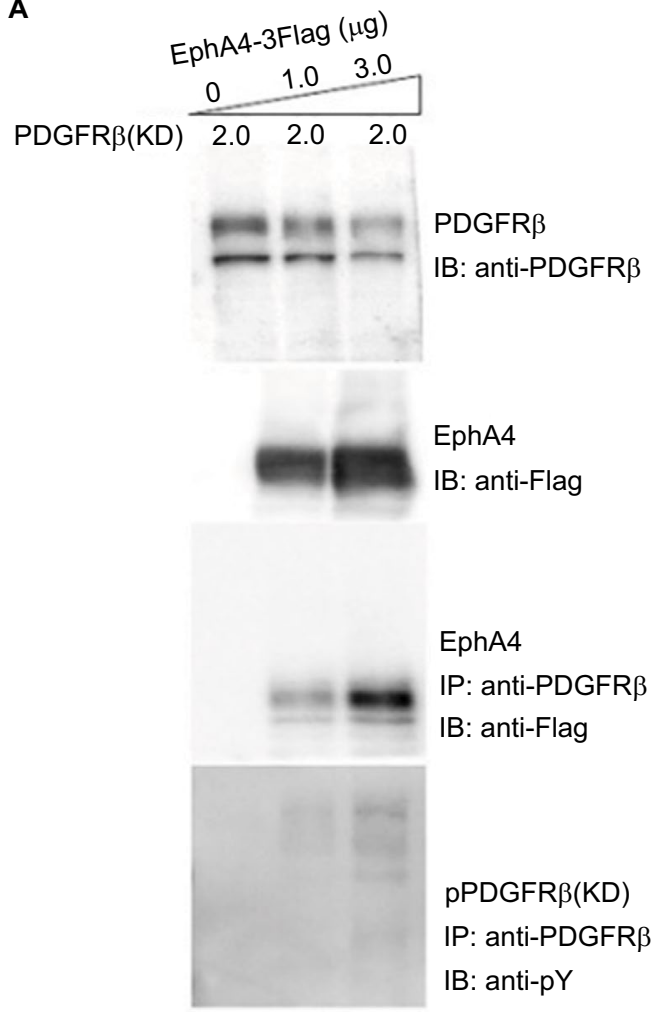

B
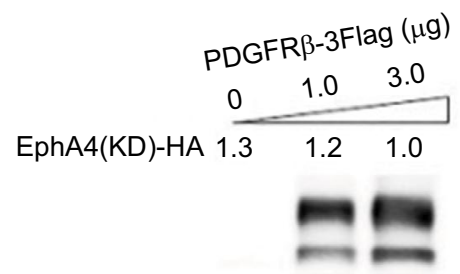

PDGFR $\beta$

IB: anti-Flag

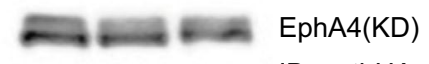

IB: anti-HA

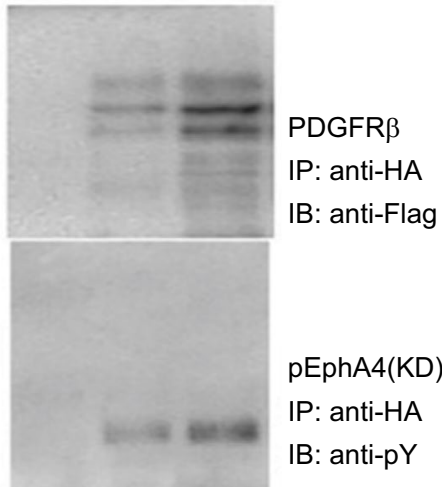

Figure 2 Tyrosine phosphorylation of EphA4 and PDGFR $\beta$ in transfected HEK293T cells.

Notes: Further direct interaction and tyrosine phosphorylation of kinase-inactive PDGFR (PDGFR $\beta(K D))$ by EphA4 (A) and the kinase-inactive EphA4(EphA4(KD)) by PDGFR $\beta$ (B). HEK293T cells were cotransfected with pcDNA/PDGFR $\beta(K D)(2 \mu g$ per $6 \mathrm{~cm}$ plate) and increasing concentrations $(0$, I, and $3 \mu \mathrm{g}$ per $6 \mathrm{~cm}$ plate) of pcDNA/ EphA4(WT) or with pcDNA/EphA4(KD)-Flag (I.3, I.2, and I.0 $\mathrm{gg}$ per $6 \mathrm{~cm}$ plate, respectively) and increasing concentrations (0, I, and $3 \mu \mathrm{g}$ per $6 \mathrm{~cm}$ plate) of pcDNA/ PDGFR $\beta(W T)$. Direct interaction was further detected by IB with anti-Flag following IP with anti-PDGFR $\beta$ or anti-HA, respectively. Tyrosine phosphorylation and expression levels of PDGFR $\beta(K D)$ or EphA4(KD) were detected by immunoblotting with anti-pY, and anti-PDGFR $\beta$, anti-Flag, or anti-Flag, anti-HA antibodies, respectively.

Abbreviations: IB, immunoblotting; IP, immunoprecipitation; PDGFR $\beta$, platelet-derived growth factor receptor $\beta$.

used to inhibit the interaction between EphA4 and FGFR to prove that EphA4 transphosphorylates FGFR. ${ }^{36,41}$ Here, we examined whether EphA4( $\triangle \mathrm{JM}, \mathrm{KD})$ could also inhibit binding of EphA4 to PDGFR $\beta$. Fixed amounts of PDGFR $\beta(2 \mu \mathrm{g}$ per $6 \mathrm{~cm}$ plate) and EphA4(WT) (1 $\mu \mathrm{g}$ per $6 \mathrm{~cm}$ plate) were coexpressed with increasing amounts of EphA4 $(\triangle \mathrm{JM}, \mathrm{KD})$ in HEK293T cells, and the binding of EphA4 to PDGFR $\beta$ was analyzed. We found that EphA4( $\triangle \mathrm{JM}, \mathrm{KD})$ inhibited the interaction between EphA4 and PDGFR $\beta$ in a dose-dependent fashion (Figure $3 \mathrm{~A})$. Results show that $\mathrm{EphA} 4(\Delta \mathrm{JM}, \mathrm{KD})$ is also a molecule that inhibits the signaling pathway through the Eph-PDGFR $\beta$ complex.

The next step was to analyze whether there is a dominantnegative effect; the expression vector for EphA4( $\triangle \mathrm{JM}, \mathrm{KD})$ was transfected into HEK293T cells together with the expression vectors for EphA4 and PDGFR $\beta$. Time course study shows that the peak of PDGFR $\beta$ tyrosine phosphorylation was at $15 \mathrm{~min}$ under PDGF-BB (100 ng/mL) stimulation (Figure 3B). When cotransfected fixed amounts of EphA4(WT) and PDGFRß(WT) in HEK293T cells, as shown in Figure $3 \mathrm{C}$, EphA4( $\triangle \mathrm{JM}, \mathrm{KD})$ significantly suppressed PDGF-BB-mediated tyrosine phosphorylation of PDGFR $\beta(\mathrm{WT})$ at either 0 or $15 \mathrm{~min}$ (the peak of ligand stimulation). Results show that the binding of EphA4 to PDGFR $\beta$ is important for both EphA4 and PDGFR $\beta$ signaling pathways.

\section{Interaction of EphA4 and PDGFR $\beta$ in the proliferation of embryonic stem cells deriving neural stem cells}

We investigated the expression patterns of EphAs and PDGFRs in the proliferative regulation of H9-NSCs. Almost all EphAs (EphA2, EphA4, EphA6, EphA7, EphA8, and EphA10) and all PDGFR family members (PDGFR $\alpha$ and PDGFR $\beta$ ) were detected in the NSCs by RT-PCR (Figure 4A and B). 
A
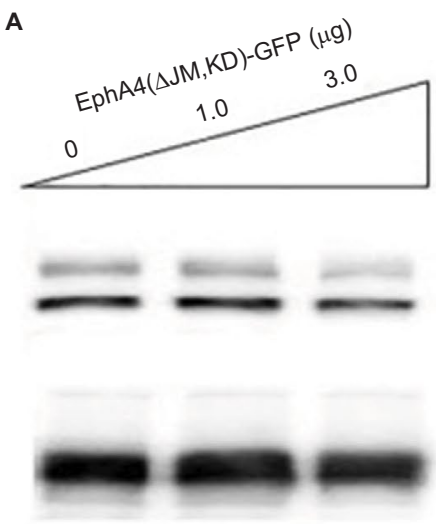

PDGF-R $\beta$ IB: anti-PDGFR $\beta$

EphA4

IB: anti-EphA4

$\operatorname{EphA4}(\triangle \mathrm{JM}, \mathrm{KD})-\mathrm{GFP}$

IB: anti-GFP

Binding

IP: anti-EphA4

IB: anti-PDGFR $\beta$
B $\begin{array}{llllllll}\text { PDGF-BB } & 0 & 5 & 15 & 30 & 60 & 120 & 180\end{array}$

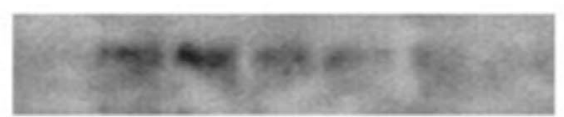

pPDGFR $\beta$

IP:anti-PDGFR $\beta$

IB:anti-pY

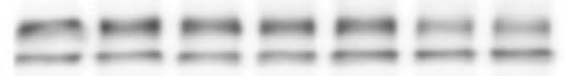

PDGFR $\beta$

IB:anti-PDGFR $\beta$

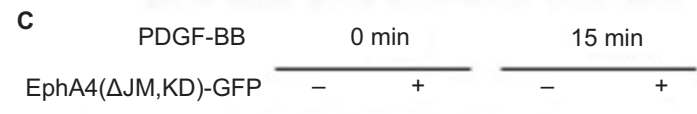

pPDGFR $\beta$

IP: anti-PDGFR $\beta$

IB: anti-pY

PDGFR $\beta$

IB: anti-PDGFR $\beta$

EphA4

IB: anti-EphA4

$\operatorname{EphA4}(\triangle \mathrm{JM}, \mathrm{KD})-\mathrm{GFP}$

IB: anti-GFP

Figure 3 Inhibition of PDGFR $\beta$-EphA4 binding by a dominant-negative EphA4.

Notes: (A) Inhibition of EphA4-PDGFR $\beta$ binding by EphA4( $\Delta \mathrm{M}, \mathrm{KD})$-green fluorescent protein (GFP). EphA4-Flag and PDGFR $\beta$ were coexpressed with increasing doses of EphA4( $\triangle J M, K D)$-EGFP in HEK293T cells, and the binding of EphA4-Flag and PDGFR $\beta$ was examined by IB with or without immunoprecipitation (IP) using the antibodies shown following SDS-PAGE. Binding of PDGFR $\beta$ with EphA4-Flag was examined with IP followed by SDS-PAGE and IB using the antibodies shown. (B and C) Inhibition of the ligand-mediated receptor phosphorylation by EphA4( $\triangle J M, K D)$, tagged with GFP. Time course of PDGF-BB mediated PDGFR $\beta$ phosphorylation (B). By using a pcDNA3.Ibased transient transfection, EphA4-Flag and PDGFR $\beta$ were coexpressed in HEK293T cells with or without EphA4(DJM,KD)-GFP, the PDGFR $\beta$ phosphorylation was examined with IP by anti-PDGFR $\beta$ followed by IB by anti-pY upon 0 and 15 min stimulation with $100 \mathrm{ng} / \mathrm{mL}$ PDGF-BB (C).

Abbreviations: IB, immunoblotting; IP, immunoprecipitation; PDGFR $\beta$, platelet-derived growth factor receptor $\beta$; SDS-PAGE, sodium dodecyl sulfate polyacrylamide gel electrophoresis.

H9-NSCs show an increase in their cell number under PDGF-BB $(20 \mathrm{ng} / \mathrm{mL})$ and/or ephrin-A1 $(0.5 \mu \mathrm{g} / \mathrm{mL})$ stimulation after a 3-day culture when seeded on a matrigelcoated plate (Figure 4C). We also evaluated the role of these ligands on cell proliferation of H9-NSCs using MTS assay (Figure 4D). Dunnett's multiple comparison test followed by two-way ANOVA depicted that the optical density increased significantly under the stimulation with ephrin-A1-Fc $(p<0.05)$ and PDGF-BB $(p<0.0001)$, respectively, compared with nonstimulation. These results suggest that activation of the cells with endogenous Ephs or PDGFRs promotes proliferation of H9-NSCs. Furthermore, the optical density showed further increase $(p<0.0001)$ under the stimulation with both ephrin-A1-Fc and PDGF-BB, suggesting enhanced proliferation of H9-NSCs by simultaneous stimulation with two ligands. Expression of the dominant-negative EphA4 or administration of STI571 (inhibitor of PDGFRs) strongly inhibited the proliferation of H9-NSCs under both ligands.

\section{Discussion}

In this report, we found that EphA4 and PDGFR $\beta$ bind to each other in a dose-dependent manner, and EphA4 and PDGFR $\beta$ transphosphorylate each other when transiently coexpressed in the same cells. A dominant-negative molecule of EphA4 can inhibit the interaction of EphA4 with PDGFR $\beta$. Stimulation with PDGF-BB and ephrin-A1-Fc enhanced neural stem cell proliferation, and the receptor complex involving EphA4 and PDGFR $\beta$ might mediate the signaling pathway.

As reported previously, we found that the cytoplasmic domains of EphA4 and FGFRs interact with each other, and the protein complex can transphosphorylate each other when overexpressed or stimulated with their ligands, which reinforces downstream signaling through activation of FRS2 $\alpha$ and ERK1/2. The receptor complex promotes NSC proliferation in response to combined simulation with ephrin-A1 and FGF2.$^{35-37}$ In this study, we have demonstrated that PDGFR $\beta$ also binds to and phosphorylates EphA4. The signal through the PDGFR $\beta /$ EphA4 complex augments NSC proliferation under the stimulation by PDGF-BB and ephrin-A1.

PDGF-BB is a member of the PDGF family comprising other four ligands (PDGF-AA, -CC, -DD, and -AB) that interact with two RTKs, PDGFR $\alpha$ and PDGFR $\beta{ }^{25-27}$ When PDGFRs are activated with ligands, they interact with and phosphorylate many downstream proteins, including the dock- 


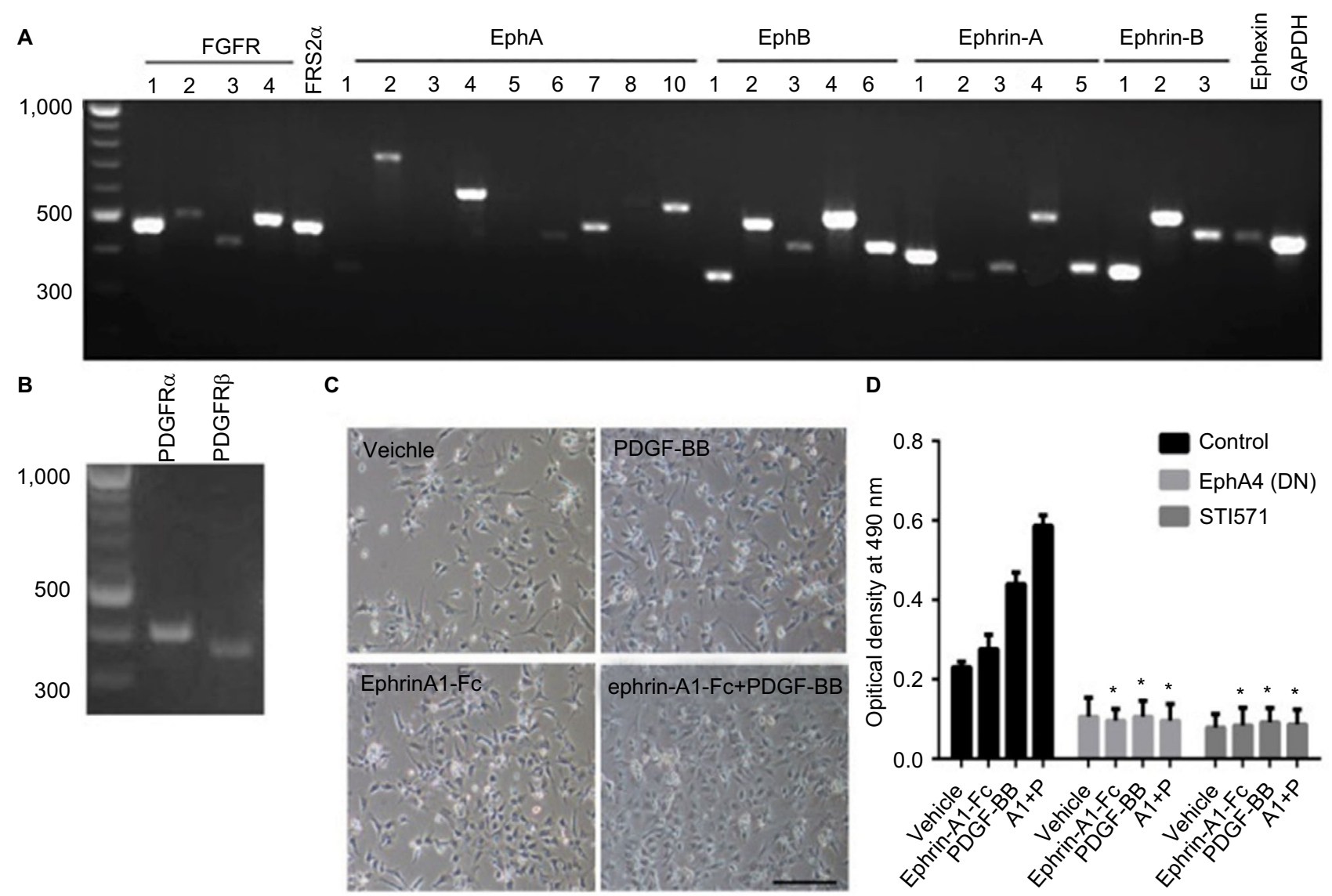

Figure 4 Interaction of Ephs and PDGFRs in the proliferation of human NSCs.

Notes: (A and B) Expression of all Eph receptors, ephrin ligands, FGFRs, PDGFRs, and related molecules in H9-NSCs. RT-PCR was performed with equal amounts of total RNA isolated from H9-NSCs. Fragment lengths are indicated on the left in base pairs. (C) Proliferation of H9-NSCs on a matrigel-coated plate. Cells were seeded as single

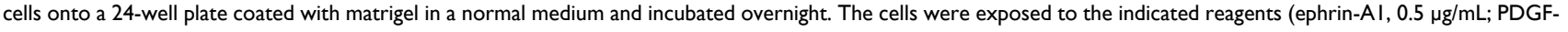
$\mathrm{BB}, 20 \mathrm{ng} / \mathrm{mL}$ ) in a growth factor-free medium and kept in the same medium for 3 days. The pictures were taken using a phase-contrast microscopy. The bar represents $100 \mu \mathrm{m}, \mathrm{N}=5$. (D) Cell proliferation of H9-NSCs was also quantitated by the 3-(4,5-dimethylthiazol-2-yl)-5-(3-carboxymethoxyphenyl)-2-(4-sulfophenyl)-2H-tetrazolium, inner salt assay in the H9-NSCs cultured in normal medium or in medium exposed with ephrin-Al and/or PDGF-BB. Some H9-NSCs bearing EphA4( $\Delta$ JM,KD) using a retrovirus vector, while some cells were pretreated with STI57I before stimulation. The absorbance at $490 \mathrm{~nm}$ of each well was measured as described in experimental procedures. Values were analyzed using two-way ANOVA followed by multiple comparison test; the error bar represents SD. * $p<0.000 \mathrm{I}$ compared to the controls. The optical density of cells incubated with ephrin-AI and/or PDGF-BB were significantly higher than that of nonstimulated cells. AI: ephrin-AI-Fc; P: PDGF-BB; N=5.

Abbreviations: NSCs, neural stem cells; PDGFR, platelet-derived growth factor receptor; RT-PCR, reverse transcription-polymerase chain reaction; ANOVA, analysis of variance.

ing proteins, FRS2 $\alpha$, which coordinately activates multiple signaling pathways through the protein complex formation. ${ }^{42}$ PDGF-BB plays key roles in the in vitro proliferation ${ }^{30}$ and neuronal differentiation of neural stem cells derived from the embryonic hippocampus. ${ }^{32}$ Furthermore, PDGF signaling prevents the cerebral hemisphere from cryogenic injury in adulthood mice. ${ }^{43}$ Conditional disruption of PDGFR $\beta$ shows deficits in fear conditioning, prepulse inhibition, spatial memory, social interaction, and forced swimming. ${ }^{44}$ EphA4 signaling mediates axon guidance, neuronal boundary formation, cell growth, angiogenesis, and cell migration. ${ }^{45}$ Deletion of EphA4 in mice shows deficiency such as hindlimb locomotion, neuron differentiation, and migration during corticogenesis, midline axon guidance, and small body size. ${ }^{35,46-48}$ Among the abnormalities during the development, resembling defects in dendritic spine density, impairment in hippocampus-dependent memory formation, and long-term potentiation are caused by deletion of either PDGFR $\beta$ or EphA4, suggesting neuron development and maturation require the presence of both PDGFR $\beta$ and EphA4..$^{21,49,50}$ These findings suggest that the PDGFR $\beta /$ EphA4 receptor complex mediates a variety of signals.

Miao et $\mathrm{al}^{51}$ reported that ephrin-A1 attenuated ERK activation through PDGF signaling and exerted the antimitogenic functions in a cell-type-specific manner. This is in contrast to our findings. The reason for this difference might be 1) we used clustered ephrin-A1 by pretreating soluble ephrinA1-Fc with anti-IgG(Fc), and 2) we used neural stem cells in our study, while Miao et al used prostatic epithelial cells and endothelial cells.

Recent reports in animal studies showed that ICV injection of either PDGF-BB for 2 weeks or clustered 
ephrin-A1-Fc for 1 week could restore production of dopaminergic neurons and achieve functional improvement in several PD animal models..$^{23,34}$ Our current findings might provide molecular evidence for curing PD with PDGF-BB and ephrin-A1. Coinjection of ephrin-A1 and PDGF-BB would be more effective in increasing dopaminergic neurons in the substantia nigra for functional recovery of Parkinsonian rat models. Stem cells may also offer a powerful new approach to model and study PD and AD. ${ }^{52,53}$ We studied the effect of transplantation of the induced pluripotent stem cells and the human umbilical blood-derived stem cells to PD or AD animal models in our laboratory and found a significant symptomatic recovery. ${ }^{54,55}$ In future, we would also like to combine the transplantation of stem cells and coinjection of ephrin-A1 and PDGF-BB to cure the neurodegenerative disease in PD and AD animal models.

\section{Conclusion}

PDGFR $\beta$ and EphA4 can mutually bind to and transphosphorylate in a dose-dependent manner when cotransfected in HEK293T cells. NSCs express PDGFRs and almost all the Ephs and ephrins. Direct interaction and transphosphorylation of EphA4 and PDGFR $\beta$ may play an important role in the proliferation of H9-derived NSCs. These NSCs appear to integrate the cell contact-dependent ephrin/Eph receptor signal with the humoral signals transduced by PDGF/PDGFR $\beta$.

\section{Acknowledgments}

All the participants in the study are appreciated. The authors are grateful to Dr Paul Lu from the University of California at San Diego for his help in preparing this manuscript and Dr Carl-Henrik Heldin from Ludwig Institute for Cancer Research for using their pcDNA3.1/PDGFR $\beta$ and pcDNA3.1/ PDGFR $\beta(K D)$ plasmids. The work was supported by National Scientific Foundation of China (NSFC 81571241, to FH), a Research Grant on Priority Areas from the Wakayama Medical University (to KS and TS), and a Research Initiative Grant for Doctor from Liaocheng People's Hospital (to QC).

\section{Disclosure}

The authors report no conflicts of interest in this work.

\section{References}

1. Schlessinger J, Lemmon MA. SH2 and PTB domains in tyrosine kinase signaling. Sci STKE. 2003;2003(191):RE12.

2. Porter AC, Vaillancourt RR. Tyrosine kinase receptor-activated signal transduction pathways which lead to oncogenesis. Oncogene. 1998;17(11 Reviews):1343-1352.

3. Yarden Y, Sliwkowski MX. Untangling the ErbB signalling network. Nat Rev Mol Cell Biol. 2001;2(2):127-137.
4. Kaushansky A, Gordus A, Chang B, Rush J, MacBeath G. A quantitative study of the recruitment potential of all intracellular tyrosine residues on EGFR, FGFR1 and IGF1R. Mol Biosyst. 2008;4(6): 643-653.

5. Kullander K, Klein R. Mechanisms and functions of Eph and ephrin signalling. Nat Rev Mol Cell Biol. 2002;3(7):475-486.

6. Nomura T, Goritz C, Catchpole T, Henkemeyer M, Frisen J. EphB signaling controls lineage plasticity of adult neural stem cell niche cells. Cell Stem Cell. 2010;7(6):730-743.

7. Khodosevich K, Watanabe Y, Monyer H. EphA4 preserves postnatal and adult neural stem cells in an undifferentiated state in vivo. $J$ Cell Sci. 2011;124(pt 8):1268-1279.

8. Hu Y, Li S, Jiang H, Li MT, Zhou JW. Ephrin-B2/EphA4 forward signaling is required for regulation of radial migration of cortical neurons in the mouse. Neurosci Bull. 2014;30(3):425-432.

9. Takeuchi S, Katoh H, Negishi M. Eph/ephrin reverse signalling induces axonal retraction through RhoA/ROCK pathway. J Biochem. 2015;158(3):245-252.

10. Wang HU, Chen ZF, Anderson DJ. Molecular distinction and angiogenic interaction between embryonic arteries and veins revealed by ephrin-B2 and its receptor Eph-B4. Cell. 1998;93(5):741-753.

11. Zhao C, Irie N, Takada Y, et al. Bidirectional ephrinB2-EphB4 signaling controls bone homeostasis. Cell Metab. 2006;4(2):111-121.

12. Xu Q, Mellitzer G, Robinson V, Wilkinson DG. In vivo cell sorting in complementary segmental domains mediated by Eph receptors and ephrins. Nature. 1999;399(6733):267-271.

13. Fukai J, Yokote H, Yamanaka R, Arao T, Nishio K, Itakura T. EphA4 promotes cell proliferation and migration through a novel EphA4FGFR1 signaling pathway in the human glioma U251 cell line. Mol Cancer Ther. 2008;7(9):2768-2778.

14. Liu Q, Guo X, Que S, et al. LncRNA RSU1P2 contributes to tumorigenesis by acting as a ceRNA against let-7a in cervical cancer cells. Oncotarget. Epub 2016 Jul 26.

15. Wang Y, Liu Z, Yao B, et al. Long non-coding RNA TUSC7 acts a molecular sponge for miR-10a and suppresses EMT in hepatocellular carcinoma. Tumour Biol. 2016;37(8):11429-11441.

16. de Marcondes PG, Bastos LG, de-Freitas-Junior JC, Rocha MR, Morgado-Diaz JA. EphA4-mediated signaling regulates the aggressive phenotype of irradiation survivor colorectal cancer cells. Tumour Biol. 2016;37(9):12411-12422.

17. de Marcondes PG, Morgado-Diaz JA. The role of EphA4 signaling in radiation-induced EMT-like phenotype in colorectal cancer cells. J Cell Biochem. 2016;118(3):442-445.

18. Jing X, Sonoki T, Miyajima M, et al. EphA4-deleted microenvironment regulates cancer development and leukemoid reaction of the isografted 4T1 murine breast cancer via reduction of an IGF1 signal. Cancer Med. 2016;5(6):1214-1227.

19. Konstantinova I, Nikolova G, Ohara-Imaizumi M, et al. EphA-EphrinA-mediated beta cell communication regulates insulin secretion from pancreatic islets. Cell. 2007;129(2):359-370.

20. Rosenberger AF, Rozemuller AJ, van der Flier WM, Scheltens P, van der Vies SM, Hoozemans JJ. Altered distribution of the EphA4 kinase in hippocampal brain tissue of patients with Alzheimer's disease correlates with pathology. Acta Neuropathol Commun. 2014;2:79.

21. Fu AK, Hung KW, Huang H, et al. Blockade of EphA4 signaling ameliorates hippocampal synaptic dysfunctions in mouse models of Alzheimer's disease. Proc Natl Acad Sci U S A. 2014;111(27): 9959-9964.

22. Shi M, Movius J, Dator R, et al. Cerebrospinal fluid peptides as potential Parkinson disease biomarkers: a staged pipeline for discovery and validation. Mol Cell Proteomics. 2015;14(3):544-555.

23. Jing X, Miwa H, Sawada T, et al. Ephrin-A1-mediated dopaminergic neurogenesis and angiogenesis in a rat model of Parkinson's disease. PLoS One. 2012;7(2):e32019.

24. Van Hoecke A, Schoonaert L, Lemmens R, et al. EPHA4 is a disease modifier of amyotrophic lateral sclerosis in animal models and in humans. Nat Med. 2012;18(9):1418-1422. 
25. Li X, Ponten A, Aase K, et al. PDGF-C is a new protease-activated ligand for the PDGF alpha-receptor. Nat Cell Biol. 2000;2(5):302-309.

26. LaRochelle WJ, Jeffers M, McDonald WF, et al. PDGF-D, a new protease-activated growth factor. Nat Cell Biol. 2001;3(5): 517-521.

27. Heldin $\mathrm{CH}$, Eriksson U, Ostman A. New members of the plateletderived growth factor family of mitogens. Arch Biochem Biophys. 2002;398(2):284-290.

28. Mohapel P, Frielingsdorf H, Haggblad J, Zachrisson O, Brundin P. Platelet-derived growth factor (PDGF-BB) and brain-derived neurotrophic factor (BDNF) induce striatal neurogenesis in adult rats with 6-hydroxydopamine lesions. Neuroscience. 2005;132(3):767-776.

29. Yang L, Chen X, Hu G, Cai Y, Liao K, Buch S. Mechanisms of platelet-derived growth factor-BB in restoring HIV Tat-cocainemediated impairment of neuronal differentiation. Mol Neurobiol. 2016;53(9):6377-6387.

30. Yao H, Duan M, Yang L, Buch S. Platelet-derived growth factor$\mathrm{BB}$ restores human immunodeficiency virus Tat-cocaine-mediated impairment of neurogenesis: role of TRPC1 channels. J Neurosci. 2012;32(29):9835-9847.

31. Yang CM, Hsieh HL, Yu PH, Lin CC, Liu SW. IL-1beta induces MMP9-dependent brain astrocytic migration via transactivation of PDGF receptor/NADPH oxidase 2-derived reactive oxygen species signals. Mol Neurobiol. 2015;52(1):303-317.

32. Yang L, Chao J, Kook YH, Gao Y, Yao H, Buch SJ. Involvement of miR-9/MCPIP1 axis in PDGF-BB-mediated neurogenesis in neuronal progenitor cells. Cell Death Dis. 2013;4:e960.

33. Zachrisson $\mathrm{O}$, Zhao M, Andersson A, et al. Restorative effects of platelet derived growth factor-BB in rodent models of Parkinson's disease. J Parkinsons Dis. 2011;1(1):49-63.

34. Paul G, Zachrisson O, Varrone A, et al. Safety and tolerability of intracerebroventricular PDGF-BB in Parkinson's disease patients. J Clin Invest. 2015;125(3):1339-1346.

35. Chen Q, Arai D, Kawakami K, et al. EphA4 regulates the balance between self-renewal and differentiation of radial glial cells and intermediate neuronal precursors in cooperation with FGF signaling. PLoS One. 2015;10(5):e0126942.

36. Sawada T, Arai D, Jing X, et al. Trans-activation between EphA and FGFR regulates self-renewal and differentiation of mouse embryonic neural stem/progenitor cells via differential activation of FRS2alpha. PLoS One. 2015;10(5):e0128826.

37. Yokote H, Fujita K, Jing X, et al. Trans-activation of EphA4 and FGF receptors mediated by direct interactions between their cytoplasmic domains. Proc Natl Acad Sci U S A. 2005;102(52):18866-18871.

38. Kadoya K, Lu P, Nguyen K, et al. Spinal cord reconstitution with homologous neural grafts enables robust corticospinal regeneration. Nat Med. 2016;22(5):479-487.

39. Vanlandewijck M, Lebouvier T, Andaloussi Mae M, et al. Functional characterization of germline mutations in PDGFB and PDGFRB in primary familial brain calcification. PLoS One. 2015;10(11): e0143407.
40. Westermark B, Siegbahn A, Heldin CH, Claesson-Welsh L. B-type receptor for platelet-derived growth factor mediates a chemotactic response by means of ligand-induced activation of the receptor proteintyrosine kinase. Proc Natl Acad Sci U S A. 1990;87(1):128-132.

41. Sawada T, Jing X, Zhang Y, et al. Ternary complex formation of EphA4, FGFR and FRS2alpha plays an important role in the proliferation of embryonic neural stem/progenitor cells. Genes Cells. 2010;15(3):297-311.

42. Chen PY, Simons M, Friesel R. FRS2 via fibroblast growth factor receptor 1 is required for platelet-derived growth factor receptor betamediated regulation of vascular smooth muscle marker gene expression. J Biol Chem. 2009;284(23):15980-15992.

43. Ishii Y, Oya T, Zheng L, et al. Mouse brains deficient in neuronal PDGF receptor-beta develop normally but are vulnerable to injury. J Neurochem. 2006;98(2):588-600.

44. Nguyen PT, Nakamura T, Hori E, et al. Cognitive and socio-emotional deficits in platelet-derived growth factor receptor-beta gene knockout mice. PLoS One. 2011;6(3):e18004.

45. Pasquale EB. Eph-ephrin bidirectional signaling in physiology and disease. Cell. 2008;133(1):38-52.

46. Dottori M, Hartley L, Galea M, et al. EphA4 (Sek1) receptor tyrosine kinase is required for the development of the corticospinal tract. Proc Natl Acad Sci U S A. 1998;95(22):13248-13253.

47. Kramer ER, Knott L, Su F, et al. Cooperation between GDNF/Ret and ephrinA/EphA4 signals for motor-axon pathway selection in the limb. Neuron. 2006;50(1):35-47.

48. Jing X, Miyajima M, Sawada T, et al. Crosstalk of humoral and cellcell contact-mediated signals in postnatal body growth. Cell Rep. 2012;2(3):652-665

49. Shioda N, Moriguchi S, Oya T, et al. Aberrant hippocampal spine morphology and impaired memory formation in neuronal plateletderived growth factor beta-receptor lacking mice. Hippocampus. 2012;22(6):1371-1378.

50. Chen W, Baylink DJ, Brier-Jones J, et al. PDGFB-based stem cell gene therapy increases bone strength in the mouse. Proc Natl Acad Sci USA. 2015;112(29):E3893-E3900.

51. Miao H, Wei BR, Peehl DM, et al. Activation of EphA receptor tyrosine kinase inhibits the Ras/MAPK pathway. Nat Cell Biol. 2001;3(5):527-530.

52. Han F, Baremberg D, Gao J, et al. Development of stem cell-based therapy for Parkinson's disease. Transl Neurodegener. 2015;4:16.

53. Han FW, Wang W, Chen C. Research progress in animal models and stem cell therapy for Alzheimer's disease. J Neurorestoratol. 2014;3:11-22.

54. Han F, Wang W, Chen B, et al. Human induced pluripotent stem cellderived neurons improve motor asymmetry in a 6-hydroxydopamineinduced rat model of Parkinson's disease. Cytotherapy. 2015;17(5): 665-679.

55. Chen C, Duan J, Shen A, Wang W, et al. Transplantation of human umbilical cord blood-derived mononuclear cells induces recovery of motor dysfunction in a rat model of Parkinson's disease. JNeurorestoratol. 2016;4:23-33.
Journal of Neurorestoratology

\section{Publish your work in this journal}

The Journal of Neurorestoratology is an international, peer-reviewed open access online journal publishing original research and review articles on the subject of Neurorestoratology. To provide complete coverage of this revolutionary field the Journal of Neurorestoratology will report on relevant experimental research, technological advances,
Dovepress

and clinical achievements. The manuscript management system is completely online and includes a very quick and fair peer-review system, which is all easy to use. Visit http://www.dovepress.com/testimonials. php to read real quotes from published authors. 